\title{
Detección de genes codificantes de enzimas modificadoras de aminoglucósidos (EMAs) en aislados clínicos de Pseudomonas aeruginosa
}

\author{
Pedro Barba ${ }^{1}$, David Ortega-Paredes ${ }^{1}$, María Fernanda Yauri ${ }^{1}$, Mercedes Rodríguez-Riglos ${ }^{1}$, \\ Jeannete Zurita ${ }^{2}$ e Iliana Alcocer ${ }^{1}$ \\ ${ }^{1}$ Laboratorio de Microbiología, Escuela de Ciencias Biológicas, Pontificia Universidad Católica del Ecuador, \\ Quito,Ecuador,pmbarba@gmail.com \\ ${ }^{2}$ Facultad de Medicina, Pontificia Universidad Católica del Ecuador, Quito, Ecuador.
}

Recibido: 04, 05, 2012; aceptado: 02, 10, 2012

\begin{abstract}
RESUMEN.- La resistencia bacteriana a antibióticos representa un grave problema de salud pública. Pseudomonas aeruginosa tiene gran relevancia debido a su alta incidencia en infecciones asociadas al cuidado de la salud. La patogenicidad de P. aeruginosa se intensifica debido a: su resistencia intrínseca o adquirida a varios agentes antimicrobianos, y al encontrarse asociada a plataformas génicas móviles como plásmidos o transposones; lo cual deriva en el surgimiento de cepas multirresistentes. Los aminoglucósidos representan un grupo de antimicrobianos fundamental en la terapia de infecciones cuyo agente etiológico es $P$. aeruginosa. El objetivo de este estudio fue detectar la presencia de genes que codifican enzimas modificadoras de aminoglucósidos (EMAs) en aislados clínicos de Pseudomonas aeruginosa. Se analizaron 78 aislados resistentes a aminoglucósidos provenientes de varios hospitales en Quito, Ecuador. La confirmación de la especie se realizó mediante la amplificación del gen oprL. Los genes codificantes de EMAs reportados con mayor frecuencia en Pseudomonas aeruginosa son: aac(3)-IIa, aac(6')-Ib, ant(2')-Ia, aph(3')-VIa. Estos genes fueron detectados mediante PCR empleando iniciadores específicos. El 64,10\% de aislados de la población de estudio presentaron genes EMAs. Los genes con mayor prevalencia fueron $a a c(3)-I I a$, $a a c\left(6^{\prime}\right)-I b$ y ant(2 ')-Ia. Los perfiles de genes EMAs más prevalentes fueron las combinaciones $a a c(3)-I I a$ y $a a c\left(6^{\prime}\right)-I b / a n t\left(2^{\prime \prime}\right)-I a$, lo cual concuerda con sus perfiles fenotípicos de resistencia. Este estudio nos permite reconocer la relación entre la resistencia a los aminoglucósidos y los mecanismos de resistencia relacionados con genes productores de enzimas modificadoras de aminoglucósidos (EMAs).
\end{abstract}

PALABRAS CLAVE: Aminoglucósidos, EMAs, infección, Pseudomonas aeruginosa, resistencia.

ABSTRACT.- Bacterial resistance to antibiotics represents a major public health issue. Pseudomonas aeruginosa constitutes a leading cause of nosocomial infections. The pathogenicity of $P$. aeruginosa is intensified by its intrinsic and acquired resistance to wide variety antibacterial agents. Acquired resistance spreads through genetic mobile elements such plasmids and transposons, leading to the emergence of multiresistant strains. Aminoglycosides represents a key family of antibacterials used to treat infections caused by P. aeruginosa. The aim of this study was to detect the presence of aminoglycoside-resistance genes in 78 resistant clinical isolates of $P$. aeruginosa from several hospitals in Quito-Ecuador. The specie confirmation was performed by amplifying the oprL gen. The most frequently reported AMEs genes in 
Pseudomonas aeruginosa: aac (3)-IIa, aac (6 ')-Ib, ant (2')-Ia, aph (3')-VIa were detected by PCR using specific primers. AMEs genes were found in $64.10 \%$ of isolates. The most prevalent genes were $a a c$ (3)-IIa, aac (6')-Ib and ant (2")-Ia. The most common profiles of AMEs genes were aac (3)-IIa, and aac (6 ')-Ib / ant (2")-Ia, consistent with phenotypic resistance profiles. This study allows us to gain better understanding of the resistance mechanisms related with genes that produce aminoglycoside modifying enzymes.

KEYWORDS: AMEs, aminoglycosides, infection, Pseudomonas aeruginosa, resistance.

\section{INTRODUCCIÓN}

La resistencia bacteriana a los antibióticos es un grave problema de salud pública que reduce de manera significativa la capacidad de los centros hospitalarios para restaurar la salud de los pacientes (Lepape y Monnet, 2009). El uso inadecuado de los agentes antimicrobianos en coordinación con la plasticidad genética bacteriana, han permitido el desarrollo de múltiples mecanismos de resistencia a cada antibiótico introducido en la práctica clínica (Davis y Davis, 2010). Los mecanismos de resistencia a antibacterianos son, con frecuencia, complejos, incluyendo la producción de enzimas que catalizan la inactivación del antibiótico, impermeabilidad de la membrana externa, sobreexpresión de bombas de eflujo y mutaciones puntuales (Tenover, 2006).

En la práctica diaria, el personal médico se ve forzado a escoger una terapia antimicrobiana en base a los síntomas de la infección. Este tipo de tratamiento se conoce como terapia empírica. La aplicación de una terapia empírica efectiva requiere, además de las consideraciones médicas para cada paciente, del conocimiento de los patrones y mecanismos de resistencia del patógeno involucrado en la infección (Páterson, 2008).

Existe una alta variación en dichos patrones y mecanismos de resistencia, la cual se encuentra influenciada por factores relacionados al lugar geográfico donde ocurre la infección. Se requiere de datos locales con el fin de aumentar la probabilidade de definir la terapia antibacteriana inicial (Livermore y Pearson, 2007) y reducir los índices de morbilidad y mortalidad; así como, el valor aso- ciado al tratamiento antimicrobiano (Ramón y Fernández-Cruz, 2008; Isturiz y Carbon, 2000).

Pseudomonas aeruginosa (Schroeter) es un importante patógeno oportunista. Se encuentra ampliamente distribuido, y en la actualidad es responsable de un gran número de infecciones, principalmente en ambientes hospitalarios (Páterson, 2008). Las infecciones producidas por $P$. aeruginosa se desarrollan en pacientes que tienen el sistema inmune comprometido o cuando se alteran las barreras normales de la piel y mucosas, generalmente, iniciadas por heridas, quemaduras, cateterizaciones, traqueotomías, punciones lumbares o transfusiones intravenosas (Livermore y Pearson, 2007; Isturiz y Carbon, 2000).

$P$. aeruginosa presenta resistencia natural a muchos antimicrobianos, como a la mayoría de las penicilinas, cefalosporinas de primera, segunda y tercera generación, cefamicinas, entre otros, debido a características relacionadas con baja permeabilidad en la membrana, producción de $\beta$-lactamasas cromosómicas de tipo AmpC, reducción de porinas y sobreexpresión de bombas de expulsión activa (Ramón y Fernández-Cruz, 2008). Además, puede desarrollar mutaciones cromosómicas y adquirir nuevos elementos genéticos que incrementan su resistencia, convirtiéndose en un patógeno multirresistente a una amplia gama de antimicrobianos disponibles para su control (Madigan et al., 2003; Cantón et al., 2002).

Los aminoglucósidos representan un componente fundamental en la terapia de infecciones causadas por $P$. aeruginosa, debido a su actividad contra bacterias Gram negati- 
vas y por exhibir sinergia con otros antibacterianos, principalmente $\beta$-lactámicos (Onguru et al., 2008). Sin embargo, su efectividad en la terapia se ha visto disminuida por la presencia de enzimas modificadoras de aminoglucósidos (EMAs), las cuales actúan principalmente sobre kanamicina, neomicina, gentamicina, amikacina y tobramicina (Martínez, 2007). Las EMAs modifican covalentemente los grupos amino e hidroxilo de los aminoglucósidos, disminuyendo la especificidad de su unión al sitio blanco en el rRNA 16S, inactivando de esta forma al antimicrobiano (Stain y Raoult, 2002).

El conocimiento detallado de la prevalencia de estos determinantes de resistencia en nuestro medio, nos permitirá el adecuado uso de dichos agentes en la terapia contra infecciones cuyo agente etiológico es $P$. aeruginosa, elevando de esta manera, la capacidad de los centros hospitales para restablecer la salud en sus pacientes. Por esta razón el objetivo de este estudio fue detectar la presencia de genes productores de EMAs en aislados hospitalarios de P. aeruginosa resistentes a aminoglucósidos.

\section{MATERIALES Y MÉTODOS}

Población de estudio.- Se analizaron 78 aislados de $P$. aeruginosa resistentes a aminoglucósidos donados por el Departamento de Microbiología de Zurita\&Zurita Laboratorios (Quito, Ecuador). Estos aislados provienen de varios centros hospitalarios de la ciudad de Quito y se muestrearon en pacientes que presentaron casos documentados de infección microbiana durante enero de 2005 y octubre de 2008. El perfil fenotípico de resistencia a amikacina, gentamicina y tobramicina, fue realizado mediante MicroScan ${ }^{\circledR}$ (Dade Behring), siguiendo los criterios de sensibilidad y lineamientos establecidos por el "Clinical and Laboratory Standards Institute", 2009. Los aislados se mantienen en la Colección Bacteriana Quito Católica del Laboratorio de Microbiología de la Escuela de Ciencias Biológicas, de la Pontificia Universidad Católica del Ecuador.

Extracción de ADN.- Para la extracción del ADN total, empleado como molde para las pruebas moleculares, se utilizó el reactivo de aislamiento para ADN genómico DNAzol ${ }^{\circledR}$ Reagent (Invitrogen), siguiendo las especificaciones del fabricante.

Identificación molecular de Pseudomonas aeruginosa.- La identificación genotípica de Pseudomonas aeruginosa, se realizó a través de la técnica de reacción en cadena de la polimerasa (PCR), mediante amplificación del gen opr L codificante de una proteína de membrana externa, único para esta especie. Los iniciadores usados (Tabla 1), así como las condiciones de amplificación, con modificaciones, fueron los descritos por $\mathrm{Xu}$ et al., 2004. La reacción de PCR fue estandarizada en un volumen de $25 \mu 1$, conteniendo: $25 \mathrm{ng}$ de ADN, $800 \mu \mathrm{M}$ de deoxinucleótidos fosfato (dNTPmix) (Promega), 0,1 $\mu \mathrm{M}$ de cada iniciador (Integrated DNA Tecnologies), 1.25 U de GoTaq Flexi DNA Polymerase (Promega), $10 \mathrm{mM}$ de Tris- $\mathrm{HCl}$ (pH 8.3), $50 \mathrm{mM}$ de $\mathrm{KCl}, 2.5 \mathrm{mM}$ de $\mathrm{MgCl}_{2}$ (Promega). Como control positivo de la reacción se empleó ADN de la cepa de $P$. aeruginosa ATCC 27853 y como control negativo se utilizó agua de graduación molecular.

El programa de amplificación se realizó en un termociclador GeneAmp PCR System 9700 (PerkinElmer). El programa consistió en una denaturación inicial a $94^{\circ} \mathrm{C}$ durante $5 \mathrm{mi}$ nutos, seguido por 30 ciclos, los cuales consistieron en un paso de denaturación a $96^{\circ} \mathrm{C}$ por 1 minuto, seguido de un paso de hibridación a $57^{\circ} \mathrm{C}$ por 40 segundos y un paso de extensión a $72^{\circ} \mathrm{C}$ por 1 minuto; $\mathrm{y}$, una extensión final a $72^{\circ} \mathrm{C}$ por 10 minutos.

Detección de genes productores de enzimas modificadoras de aminoglucósidos (EMAs).- La detección de genes EMAs se realizó mediante PCR, amplificando genes específicos, los cuales han sido identificados como productores de enzimas que modifican 
Tabla 1. Iniciadores utilizados para la detección de genes codificantes para el gen oprLy EMAs.

\begin{tabular}{|c|c|c|c|c|}
\hline Gen & Iniciador & Secuencia nucleotídica 5’ - 3' & $\mathrm{pb}$ & Referencia \\
\hline \multirow{2}{*}{ oprL } & oprLF & ATGGAAATGCTGAAATTCGGC & 504 & Xu et al., 2004 \\
\hline & oprLR & CTTCTTCAGCTCGACGCGACG & & Xu et al., 2004 \\
\hline \multirow[t]{2}{*}{$\operatorname{aac}(3)-I I a$} & aac(3)-IIa-F & CGCTAAACTCCGTTACC & 196 & Díaz et al., 2004 \\
\hline & aac(3)-IIa-R & TAGCACTGAGCAAAGCC & & Díaz et al., 2004 \\
\hline \multirow[t]{2}{*}{$a a c\left(6^{\prime}\right)-I b$} & $\operatorname{aac}\left(6^{\prime}\right)-\mathrm{Ib}-\mathrm{F}$ & TATGAGTGGCTAAATCGAT & 395 & Díaz et al., 2004 \\
\hline & $\mathrm{aac}\left(6^{\prime}\right)-\mathrm{Ib}-\mathrm{R}$ & CCCGCTTTCTCGTAGCA & & Díaz et al., 2004 \\
\hline \multirow[t]{2}{*}{$\operatorname{ant}(2 ")-I a$} & $\operatorname{ant}(2 ")-$ Ia-F & CGTCATGGAGGAGTTGGACT & 304 & Díaz et al., 2004 \\
\hline & ant (2")-Ia-R & CGCAAGACCTCAACCTTTTC & & Díaz et al., 2004 \\
\hline \multirow[t]{2}{*}{$a p h\left(3^{\prime}\right)-V I a$} & $\operatorname{aph}\left(3^{\prime}\right)-$ VIa-F & ATACAGAGACCACCATACAGT & 234 & Vila et al., 1999 \\
\hline & $\operatorname{aph}\left(3^{\prime}\right)-V I a-R$ & GGACAATCAATAATAGCAAT & & Vila et al., 1999 \\
\hline
\end{tabular}

pb, pares de bases; A, adenina; C, citosina; G, guanina; T, timina; oprL, gen de proteína de membrana externa único de Pseudomonas aeruginosa; EMAs genes productores de enzimas modificadoras de aminoglucósidos.

antibióticos pertenecientes al grupo de los aminoglucósidos, descritos por Shaw et al., 1993. Los iniciadores utilizados en esta sección se encuentran detallados en la Tabla 1 (Díaz et al., 2004; Vila et al., 1999).

Las condiciones de amplificación fueron las descritas por Díaz et al., 2004, con modificaciones. La reacción de PCR se la estandarizó en un volumen de $25 \mu \mathrm{l}$ incluyendo: $25 \mathrm{ng}$ de ADN; GoTaq ${ }^{\circledR}$ Green Master Mix (Promega), el cual contiene $1.5 \mathrm{mM}$ de $\mathrm{MgCl}_{2}, 800 \mu \mathrm{M}$ de dNTPs, $1 \mathrm{U}$ de GoTaq ${ }^{\circledR}$ DNA Polymerase y 1 X Green GoTaq ${ }^{\circledR}$ Reaction Buffer ( $\mathrm{pH} 8.5$ ); $25 \mathrm{pM}$ de cada iniciador (Integrated DNA Tecnologies); se adicionó $\mathrm{MgCl}_{2}$ para llegar a la concentración final de $3 \mathrm{mM}$; y agua grado molecular hasta alcanzar el volumen final de reacción. Como controles positivos se utilizaron las cepas 57 KPN-BLEE para el gen aac(3)-IIa, la cepa 68 KPN-BLEE para el gen aac (6')-Ia, la cepa 58 KPN-BLEE para el gen ant (2")-Ia (Ortega 2010) y la cepa 333 Ps aer, para el gen $\operatorname{aph}\left(3^{\prime}\right)$-VIa. Como control negativo se utilizó agua de grado molecular.

El proceso de amplificación del ADN se realizó en un termociclador GeneAmp PCR System 9700 (PerkinElmer). El programa consistió en una denaturación inicial a $96^{\circ}$ C durante 5 minutos, seguido de 30 ciclos con denaturación a $96^{\circ} \mathrm{C}$ durante 30 segundos, hibridación a $55^{\circ} \mathrm{C}$ durante 1 minuto y extensión a $72^{\circ} \mathrm{C}$ durante 3 minutos; seguido de una extensión final a $72^{\circ} \mathrm{C}$ durante 8 minutos.

Análisis de los productos de amplificación.- Los productos de PCR fueron analizados mediante electroforesis horizontal en geles de agarosa al $1 \%$ en tampón TBE $1 \mathrm{X}$. El programa de electroforesis consistió en la aplicación de $8 \mathrm{~V} / \mathrm{cm}$ durante 50 minutos en tampón TBE $0.5 \mathrm{X}$. La tinción del gel se realizó empleando SybrGold (Invitrogen). Los resultados fueron fotodocumentados en un sistema de captura de imagen MiniBIS Pro. La longitud de los fragmentos fue calculada empleando el programa informático GelAnalyzer versión 2010a freeware.

\section{RESULTADOS}

Los 78 aislados analizados fueron confirmados como Pseudomonas aeruginosa mediante la amplificación de un fragmento de 500 $\mathrm{pb}$, correspondiente al gen oprL (Figura 1). 


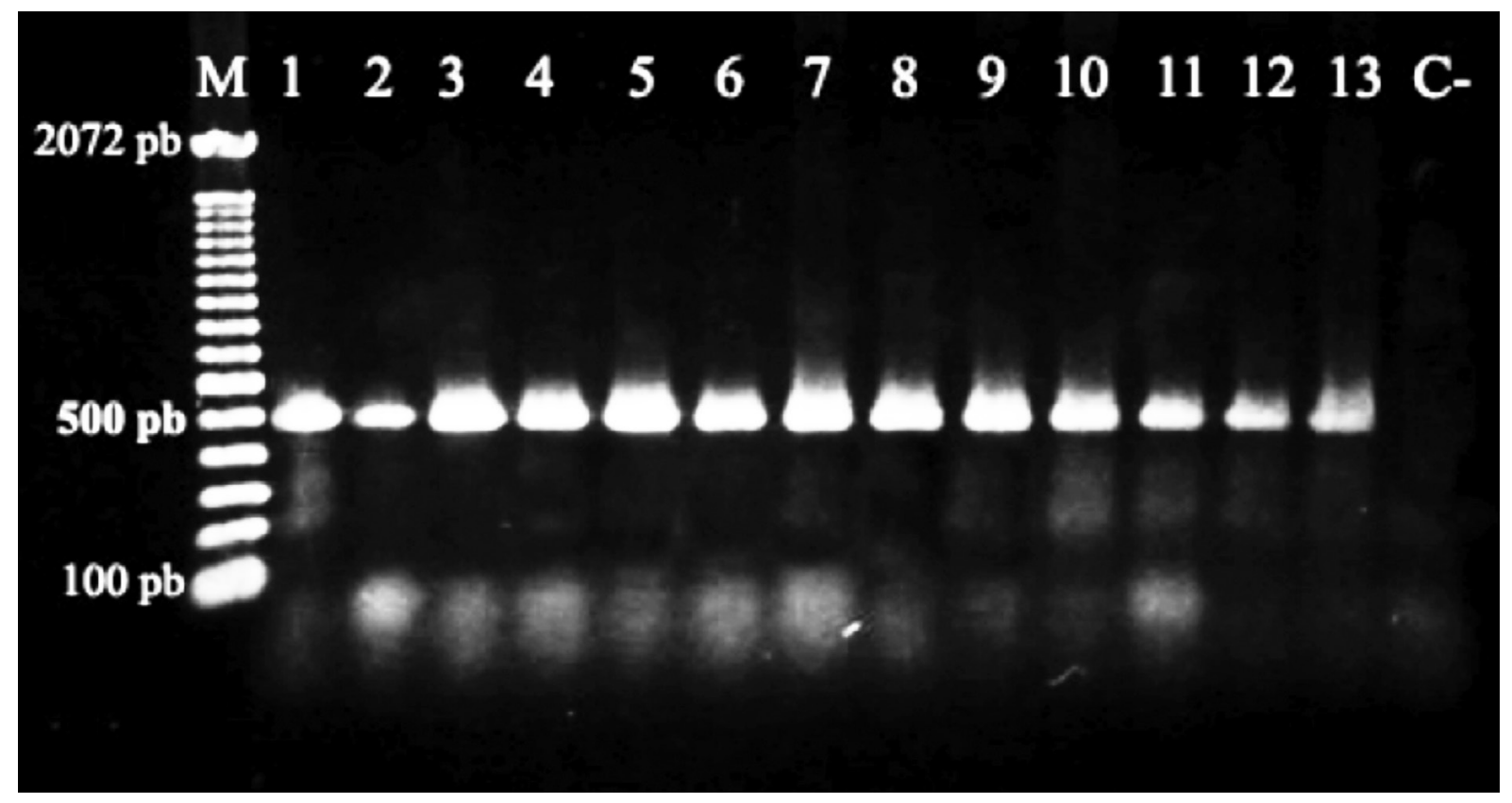

Figura 1. Gel representativo del producto de aplificación del gen de proteína de membrana externa oprL (504 pb). M, marcador de peso molecular (100 pb). Las canaletas 1 a la 12 pertenecientes a diferentes aislados de $P$. aeruginosa y presentan bandas con un peso molecular aproximado de $500 \mathrm{pb}$ correspondientes al gen oprL, único de P. aeruginosa; comprobando así, la especie de estudio. 1, 13 Ps aer; 2, 16 Ps aer; 3, 17 Ps aer; 4, 21 Ps aer; 5, 23 Ps aer; 6, 28 Ps aer; 7, 29 Ps aer; 8, 31 Ps aer; 9, 38 Ps aer; 10, 44 Ps aer; 11, 45 Ps aer; 12, 48 Ps aer; La canaleta 13 presenta la banda del amplicón de PCR de la cepa ATCC 27853 Pseudomonas aeruginosa utilizada como control positivo; C-, control negativo.

De los 78 aislados resistentes a aminoglucósidos 16 aislados $(20.51 \%)$ presentaron resistencia únicamente a gentamicina, 1 aislado $(1.28 \%)$ presentó resistencia sólo a amikacina y no se encontró aislados resistentes únicamente a tobramicina $(0.00 \%)$. Por otra parte 20 aislados $(25.64 \%)$ mostraron resistencia conjunta a gentamicina y tobramicina, 5 aislados $(6.41 \%)$ mostraron resistencia a amikacina y gentamicina, no se encontraron aislados con el perfil de resistencia amikacina y tobramicina $(0.00 \%)$. treinta y seis aislados $(46.15$ $\%$ ) mostraron resistencia a los tres antibióticos (Figura 2).

El resultado del análisis mediante el programa informático GelAnalizer, documentó pesos moleculares de $196 \mathrm{pb}$ para el gen $a a-$ $c(3)-I I a, 390 \mathrm{pb}$ para el gen $a a c\left(6^{\prime}\right)-I b, 300$ pb para el gen ant (2")-Ia y $230 \mathrm{pb}$ para el gen $\operatorname{aph}\left(3^{\prime}\right)-V I a$; confirmando la presencia de los genes estudiados (Figura 3).
De los 78 aislados analizados, 50 (64.10\%) presentaron al menos uno de los cuatro genes EMAs referentes en este estudio, mientras que los 28 aislados restantes $(35.90$ $\%)$ no evidenciaron la presencia de genes. Diecinueve aislados (24.40\%) presentaron únicamente el gen $\operatorname{aac}(3)-I I a, 11$ (14.10\%) aislados presentaron sólo el gen $a a c\left(6^{\prime}\right)-I b$, $4(5.13 \%)$ presentaron sólo el gen ant(2”)-Ia y ningún aislado fue identificado únicamente con el gen aph(3')-VIa. En los aislados restantes, se logró identificar diferentes perfiles de presencia para genes EMAs; así, el perfil $a a c\left(6^{\prime}\right)-I b / a n t(2$ ')-Ia se identificó en 6 aislados (7.69\%), el perfil aac(3)-IIa / aph(3')-VIa se identificó en 4 aislados (5.13\%), el perfil aac(3)-IIa / aac(6')-Ib se identificó en 3 aislados (3.85\%), el perfil ant(2')-Ia / aph(3')-VIa se identificó en 2 aislados $(2.56 \%)$ y el perfil aac(3)-IIa / aac(6')-Ib / ant(2')-Ia se identificó sólo en un aislado (1.28 \%); ningún aislado presentó los cuatro genes (Figura 4). 


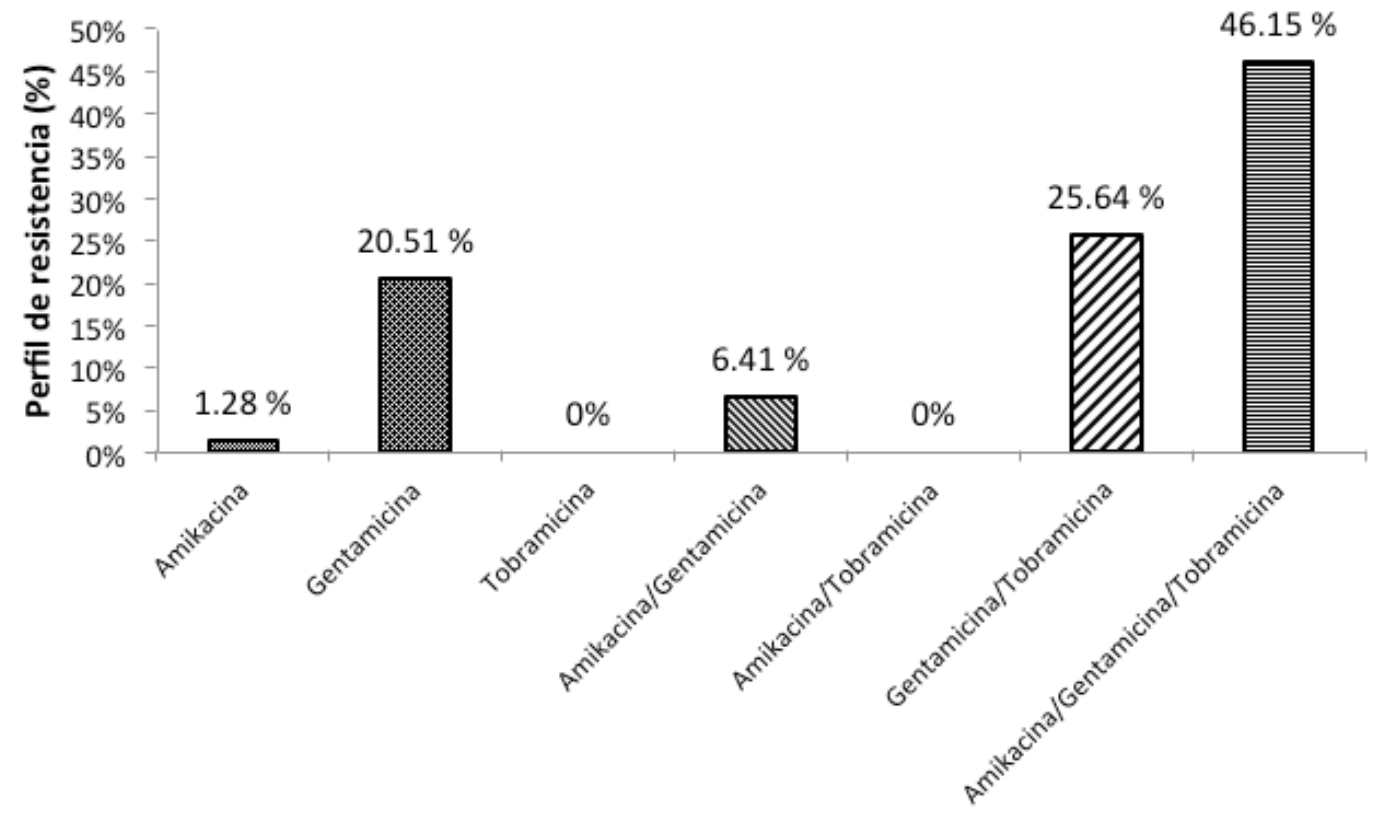

Perfil Fenotípico

Figura 2. Porcentaje de los diferentes Perfiles de resistencia a aminoglucósidos encontrados en los aislados hospitalarios de Pseudomonas aeruginosa. El total de la población resistente a aminoglucósidos fue de 78 aislados.

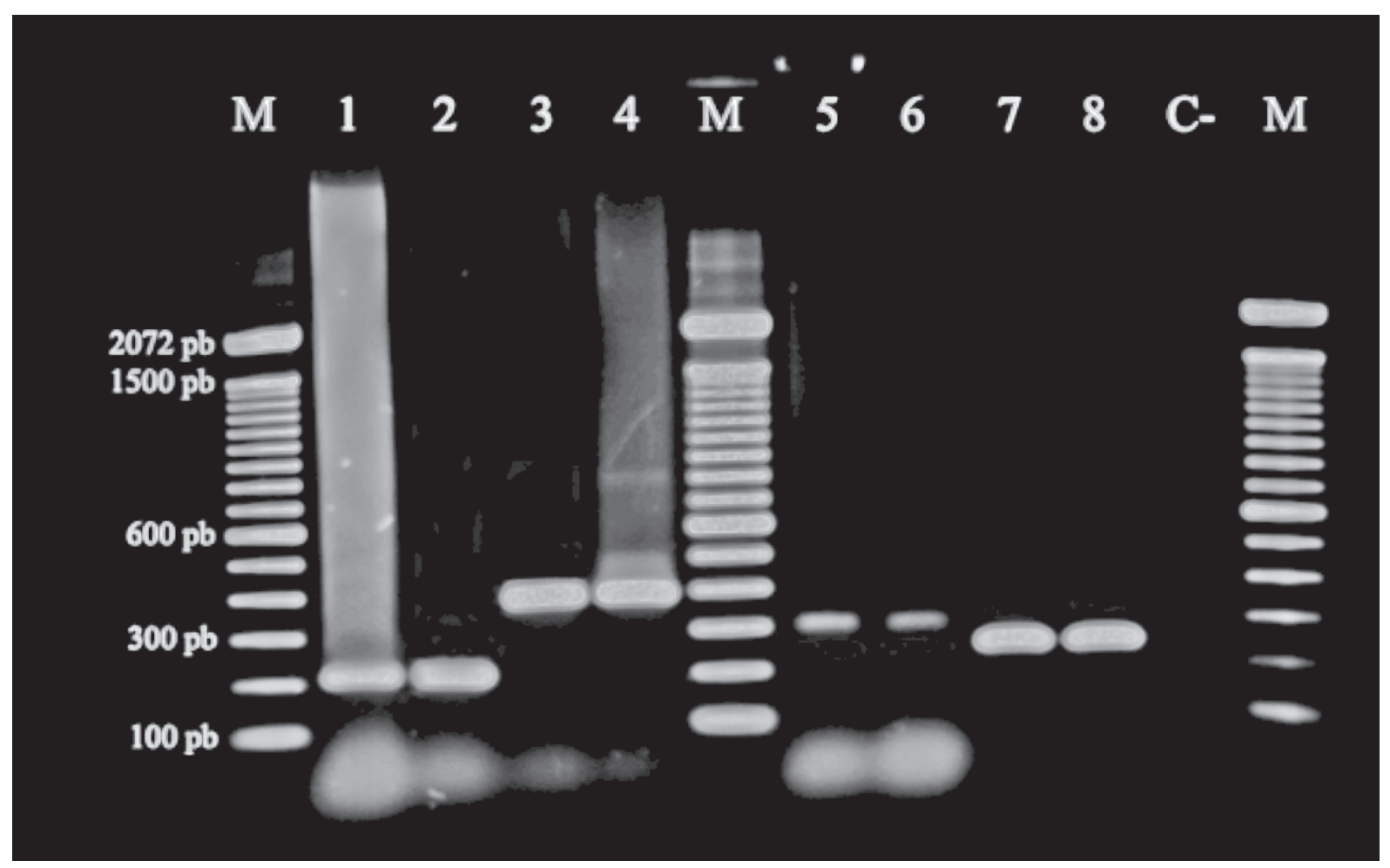

Figura 3. Gel representativo de los productos de amplificación de genes EMAs en Pseudomonas aeruginosa. M, marcador de peso molecular (100 pb). 1 y 2, bandas de peso molecular aproximado a $200 \mathrm{pb}$ correspondiente al gen aac(3)-IIa; 1, 377 Ps aer; 2, cepa control 57 KPN-BLEE. 3 y 4, bandas de peso molecular aproximado a $400 \mathrm{pb}$ correspondiente al gen $a a c\left(6^{\prime}\right)-I b ; 3,373$ Ps aer; 4, cepa control 68 KPN-BLEE. 5 y 6, bandas de peso molecular aproximado a $300 \mathrm{pb}$ correspondiente al gen ant(2")-Ia; 5, 318 Ps aer; 6, cepa control 58 KPN-BLEE. 7 y 8, bandas con peso molecular aproximado a $250 \mathrm{pb}$ pertenecientes al gen $a p h\left(3^{\prime}\right)-V I a ; 7,263$ Ps aer; 8, aislado control 333 Ps aer; C-, control negativo. 


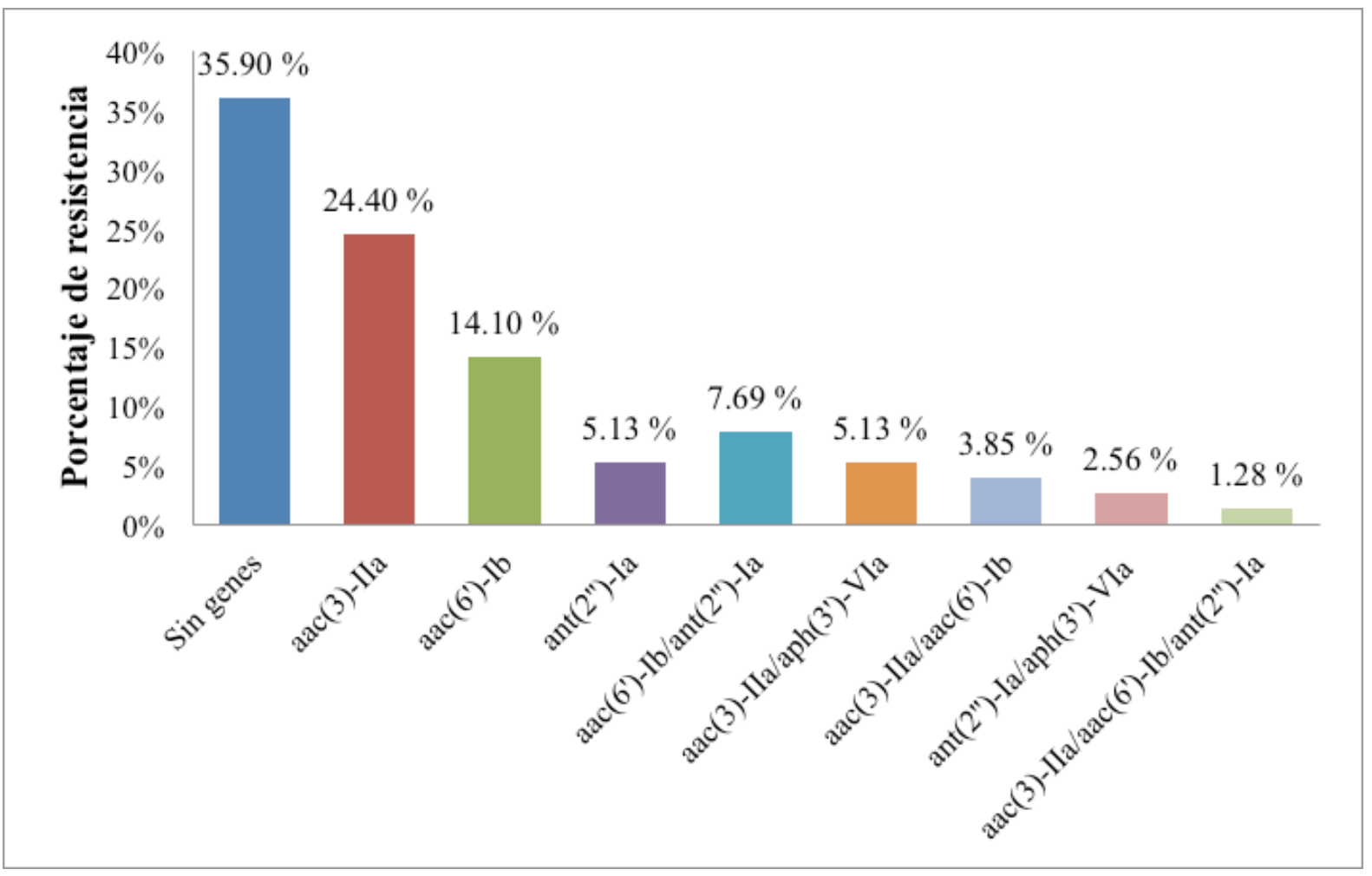

Figura 4. Porcentaje de los perfiles genotípicos encontrados para genes EMAs en aislados de Pseudomonas aeruginosa resistentes a aminoglucósidos.La población resistente a aminoglucósidos fue de 78 aislados.

\section{DISCUSIÓN}

La resistencia bacteriana a aminoglucósidos en infecciones ocasionadas por Pseudomonas aeruginosa ha sido reportada en varios países alrededor del mundo, con especial énfasis, en Latinoamérica y Europa (Poole, 2005; Andrade et al., 2003; Vakulenko y Mobashery, 2003; Gales et al., 2001). Los altos porcentajes de resistencia a los aminoglucósidos analizados en este estudio, concuerdan con lo reportado por la Red Nacional de Vigilancia de Resistencia Bacteriana-Ecuador, REDNARBEC, 2008 y con porcentajes reportados en otros estudios (Shahid y Malik, 2005; Vakulenko y Mobashery, 2003).

Diversos estudios han registrado porcentajes altos de resistencia a gentamicina en aislados de $P$. aeruginosa de origen nosocomial (Shahid y Malik, 2005; Stratchounskil et al., 1998). En el presente estudio se registró un alto porcentaje de aislados resistentes a gentamicina $(60.46 \%)$; fenómeno posiblemente relacionado a los patrones de prescripción regio- nales: su generalizado uso empírico (García y Yturralde, 2005; Mella et al., 2004), esto a pesar de poseer una toxicidad importante (Mella et al., 2004; Mingeot-Leclercq y Tulkens, 1999). Adicionalmente, se ha registrado una prevalencia alta de genes que codifican para enzimas modificadoras de aminoglucósidos, que confieren resistencia a esta droga (Shaw et al., 1993). En concordancia, en este trabajo se observaron patrones similares de prevalencia, en donde, los genes EMAs relacionados con la resistencia a gentamicina, alcanzaron niveles cercanos al $50.00 \%$.

Antibióticos tales como tobramicina, amikacina (analizados en este estudio), neomicina y netilmicina; se encuentran sujetos a iguales fenómenos de surgimiento de resistencia y diseminación de la misma (Guerrero et al., 2003). Sin embargo, restricciones en su uso, como dosificación y uso tópico, han limitado la presión selectiva, la cual ayuda a mantener niveles altos de sensibilidad (Poole, 2005; Schmitz et al., 1999). No obstante, el 
presente estudio registró resistencia a estos antibióticos en tasas relativamente altas, al igual que los determinantes genéticos involucrados e incluidos en el estudio (Shaw et al., 1993).

A pesar de la presencia de cepas de $P$. aeruginosa resistentes a aminoglucósidos en el medio hospitalario, estos compuestos mantienen su vigencia en la terapia de infecciones ocasionadas por este patógeno (Poole, 2005; Mella et al., 2004; Vakulenko y Mobashery, 2003), debido, especialmente, a su frecuente uso en sinergia con antibióticos de otras familias (en su mayoría $\beta$-lactámicos con actividad contra $P$. aeruginosa), principalmente en casos de neumonía bacteriana (Poole, 2005; Vallés y Mariscal, 2005; Organización Panamericana de Salud, 2004). Dicha característica es de gran utilidad en el tratamiento de infecciones graves causadas por $P$. aeruginosa, la cual puede reducir el uso de agentes antibacterianos de última generación, como carbapenemes (Vallés y Mariscal, 2005), aportando tanto a la vigencia de estos compuestos, como a conservar líneas de defensa para casos de infección con cepas resistentes a aminoglucósidos (Poole, 2005); además de reducir el costo del tratamiento (Mingeot-Leclercq y Tulkens, 1999).

La tasa de resistencia bacteriana a los aminoglucósidos, al igual que a otros antimicrobianos, experimenta importantes variaciones, probablemente ocasionadas por diferencias en los patrones de prescripción y dosificación de los antibióticos, observado entre países y regiones. Adicionalmente, la calidad en las prácticas y programas de control y vigilancia de infecciones nosocomiales aportan al surgimiento de perfiles localizados de resistencia (Poole, 2005; Vakulenko y Mobashery, 2003). La mayor resistencia observada a gentamicina en este estudio, puede ser el resultado de dichas diferencias en las políticas del uso de antimicrobianos. La prescripción preferencial de dicho antibiótico, en la terapia de infecciones ocasionadas por $P$. aeruginosa, sugiere una correlación con la resistencia presentada por los aislados estudiados (Aliño et al., 2007; Organización Pana- mericana de la Salud, 2004). De igual forma, propone una sincronía con la prevalencia del gen $\operatorname{aac}(3)$-IIa observada en mayor porcentaje en el análisis molecular. Este gen confiere resistencia a gentamicina, tobramicina, dibekacina y sisomicina, más no a amikacina; siendo el principal componente genético de resistencia a aminoglucósidos. Anteriormente se ha reportado a los productos de genes pertenecientes al grupo aac(3)-II como el principal mecanismo de resistencia a aminoglucósidos en Pseudomonas aeruginosa (Zurita, 2005).

En consecuencia, la alta resistencia hacia tobramicina, puede deberse a la relación genética que comparte con la resistencia a gentamicina (Vakulenko y Mobashery, 2003; Shaw et al., 1993). Caso similar es descrito en Estados Unidos, en donde la predominancia encontrada del gen ant(2")- $I$, responsable de la resistencia a gentamicina, es ocasionada por la propensión hacia el uso de este antimicrobiano en la terapia de infecciones ocasionadas por $P$. aeruginosa (Vakulenko y Mobashery, 2003). El gen ant(2')-Ia arrojó un porcentaje moderadamente alto en este estudio.

De igual manera, el alto porcentaje en el que se registraron los perfiles de resistencia gentamicina y gentamicina/tobramicina, dentro de este trabajo, puede ser el resultado de la prevalencia de los perfiles genotípicos $a a-$ $c(3)-I I a$ y $a a c\left(6^{\prime}\right)-I b / a n t\left(2^{\prime \prime}\right)-I a$; este último perfil genético confiere, además, resistencia a amikacina. El nivel alto de resistencia a amikacina se ve reflejado, por el alto índice de ocurrencia del gen $a a c\left(6^{\prime}\right)-I b$ (Poole, 2005; Shaw et al., 1993).

La capacidad de los aislados para producir enzimas modificadoras de aminoglucósidos (EMAs) se estableció determinando la presencia o ausencia de los elementos genéticos que los codifican. Los genes analizados fueron aquellos reportados con mayor frecuencia en aislados clínicos de Pseudomonas aeruginosa. Shaw et al., 1993, realizó un estudio que incluyó 728 aislados de $P$. aeruginosa, en el cual, los genes con mayor incidencia encontrados fueron $a a c(3)-I I a$, 
aac(6')-Ib, ant(2')-Ia y aph(3')-VIa. Similares resultados, fueron los arrojados por Díaz et al., 2004 y Vakulenko y Mobashery, 2003.

La inactivación mediada por enzimas modificadoras de aminoglucósidos es el principal mecanismo de resistencia bacteriana a esta familia de antimicrobianos (Poole, 2005; Mella et al., 2004; Shaw et al., 1993). Sin embargo, la existencia de mecanismos alternos de resistencia descritos para aminoglucósidos, tales como: impermeabilidad de la membrana externa, ocasionada por mutaciones en porinas; eflujo del antimicrobiano, mediado por sobreexpresión de sistemas de expulsión activa; y mutaciones en el sitio blanco 16s rRNA (Poole, 2005; Mella et al., 2004; Shaw et al., 1993), juegan un papel importante en los porcentajes de resistencia a estos antimicrobianos, aumentando la complejidad de su epidemiología (Vakulenko y Mobashery, 2003).

En el presente trabajo, el $33.90 \%$ de aislados de la población de estudio no presentó genes EMAs. Consecuentemente, en los aislados que no presentaron genes EMAs, la resistencia observada a aminoglucósidos podría ser esperada por la existencia de uno o varios de los mecanismos de resistencia mencionados. La impermeabilidad de membrana externa, el eflujo del antimicrobiano y mutaciones en el sitio blanco, no fueron incluidos en este estudio.

Al igual que otros mecanismos de resistencia, los genes productores de EMAs se encuentran localizados frecuentemente en plataformas genéticas móviles, tales como plásmidos y transposones (Mella et al., 2004; Vakulenko y Mobashery, 2003; Mengeot-Leclercq y Tulkens, 1999). Sin embargo, varios estudios han localizado ciertos genes EMAs, (ant(2")-I y aac (6')-I, por ejemplo), dentro de integrones, con mayor frecuencia que otros determinantes genéticos de resistencia, lo cual puede explicar, en parte, la ubicuidad de dichos genes y el aparecimiento de cepas multiresistentes (Xu et al., 2004; Reyes et al., 2003).

\section{CONCLUSIONES}

Los resultados del presente estudio representan el primer reporte de la presencia de aislados clínicos de Pseudomonas aeruginosa con resistencia a aminoglucósidos mediada por la acción de enzimas modificadoras de aminoglucósidos (EMAs) en Ecuador.

Existe un alto porcentaje de aislados clínicos de $P$. aeruginosa resistentes a aminoglucósidos que presentan enzimas modificadoras de aminoglucósidos como mecanismo de resistencia, lo cual, nos indica que al momento de hacer uso esta familia de antimicrobianos se debe tener conciencia de este fenómeno para evitar fracaso terapéutico, diseminación de cepas resistentes, aparecimiento de multirresistencia y la transmisión de estos genes a otros agentes etiológicos.

\section{AGRADECIMIENTOS}

Los autores desean agradecer al grupo de trabajo del laboratorio de Microbiología de la Escuela de Ciencias Biológicas, PUCE, Quito, a todo el personal de Zurita\&Zurita Laboratorios. Además, a la Pontificia Universidad Católica del Ecuador y a la donación voluntaria del Impuesta a la Renta 2009 por el apoyo económico que hizo posible la realización de este estudio a través del proyecto "Determinación de genes que codifican la resistencia a carbapenemes y aminoglucósidos en Pseudomonas aeruginosa".

\section{REFERENCIAS BIBLIOGRÁFICAS}

Aliño M, Esquirol J, Navarro R y Duperval P. 2007. Aminoglucósidos: mirada actual desde su historia. Revista Cubana de Pediatría, 79(2).

Andrade SS, Jones RN, Gales AC y Sader HS. 2003. Increasing prevalence of antimicrobial resistance among Pseudomonas aeruginosa isolates in Latin American medical centers: 5 year report of the SENTRY Antimicrobial Surveillance Program (1997-2001). Journal of Antimicrobial Chemotherapy, 52: 140-141. 
Cantón R, Girón R, Martínez L, Oliver A, Solé A, Valdezate S y Máiz L. 2002. Patógenos multiresistentes en la fibrosis quística. Archivos de Bronco neumología, 38: 376-385.

Clinical and laboratory Standards Institute. 2009. Performance standards for antimicrobial susceptibility testing; nineteenth informational supplement and Sixteenth International Supplement. CLSI document. Clinical and Laboratory Standards Institute. Wayne, Pennsylvania, USA.

Davies J y Davies D. 2010. Origins and Evolution of Antibiotic Resistance. Microbiology and Molecular Biology Reviews, 74(3): 417.

Díaz P, Bello H, Domínguez M, Trabal N, Mella S, Zemelman R y González G. 2004. Resistencia a gentamicina, amikacina y ciprofloxacina en cepas hospitalarias de Klebsiella pneumoniae subespecie pneumoniae productoras de $\beta$-lactamasas de espectro extendido. Revista Médica de Chile, 132: 1173-1178.

Gales AC, Jones RN, Turnidge J, Rennie R y Rampha R. 2001. Characterization of Pseudomonas aeruginosa isolates: Occurrence rates, antimicrobial susceptibility patterns, and molecular typing in the Global SENTRY Antimicrobial Surveillance Program, 1997-1999. Clinical Infectious Diseases, 32: 146-55.

García TP y Yturralde AS. 2005. Evaluación de la prescripción de gentamicina en gestantes ingresadas con infección del tracto urinario. Revista Cubana de Obstetricia y Ginecología.

Guerrero C, Cesteros R, Miranda A, Menasalvas A, Blázquez R y Segobia M. 2003. Sensibilidad a antimicrobianos de aislados clínicos de Pseudomonas aeruginosa. Revista Española de Quimioterapia, 16(4): 444-449.

Isturiz RE y Carbon C. 2000. Antibiotic use in developing countries. Infection Control Hospital Epidemiology, 21: 394-403.

Lepape A y Monnet DL. 2009. On behalf of participating members of the European Society of Intensive Care Medicine (ESICM). Experience of European intensive care physicians with infections due to antibiotic-resistant bacteria. Euro Survey 14(45): 19393.

Livermore DM y Pearson A. 2007. Antibiotic resistance: location, location, location. Clinical Microbiology infection, 2: 7-16.

Madigan M, Martinko J y Parker J. 2003. Brock Biología de los Microorganismos. Octava Edición. Prentice Hall Hispanoamericana. Madrid, España.

Martínez L. 2007. Pseudomonas aeruginosa: Aportación al conocimiento de su estructura y al de los mecanismos que constituyen a su resistencia a los antibióticos. Tesis Doctoral, Universitat de Barcelona. Barcelona, España.

Mella S, Sepúlveda MA, González GR, Bellot H, Domínguez MY, Zemelman RZ y Ramírez CG. 2004. Aminoglucósidos-aminociclitoles: Características estructurales y nuevos aspectos sobre su resistencia. Revista Chilena de Infectología, 21(4): 330-338.

Mingeot-Leclercq MP y Tulkens PM. 1999. Aminoglycosides: Nephrotoxicity. Antimicrobial Agents and Chemotherapy, 43(5): 1003-1012.

Onguru P, Erbay A, Bodur H, Baran G, Akinci E, Balaban N y Cevik M. 2008. Imipenem-resistant Pseudomonas aeruginosa: Risk factors for Nosocomial Infection. The Korean Academy of Medical Sciences, 23: 982-987.

Organización Panamericana de Salud. 2004. Guía para el tratamiento de enfermedades infecciosas. (OPS/DPC/CD/296/2004). Washington D.C.

Ortega D. 2010. Genotipaje de la resistencia a antibióticos en aislados clínicos de Klebsiella pneumoniae productores de $\beta$-Lactamasas de espectro extendido (BLEE). Tesis de Licenciatura. Pontificia Universidad Católica del Ecuador. Quito, Ecuador. 
Páterson DL. 2008. Impact of Antibiotic Resistance in Gram-Negative Bacilli on Empirical and Definitive Antibiotic Therapy. Clinical Infectious Diseases, 47: 14-20.

Poole K. 2005. Aminoglycoside resistance in Pseudomonas aeruginosa. Antimicrobial Agents and Chemotherapy, 49(2): 479487.

Ramón P y Fernández-Cruz A. 2008. Magnitude and tread of antibiotic resistance in Gram negative nosocomial infection in Latin America. Revista Panamericana de Infectología, 10(4): 38-46.

Red Nacional de Resistencia Bacteriana Ecuador. Página de internet: http://www. Rednarbec.org. Consultado 15-agosto-2012.

Reyes A, Bello H, Domínguez M, Mella S, Zemelman R y González G. 2003. Prevalence and types of class 1 integrons in aminoglycoside-resistant Enterobacteriaceae from several Chilean hospitals. Journal of Antimicrobial Chemotherapy, 51: 317-321.

Schmitz FJ, Verhoef J, Fluit AC y the SENTRY Participants Group. 1999. Prevalence of aminoglycoside resistance in 20 European University Hospitals participating in the European SENTRY Antimicrobial Surveillance Programme. European Journal of Clinical Microbiology \& Infectious Diseases, 18: 414-42.

Shahid M y Malik A. 2005. Resistance due to aminoglycoside modifying enzymes in Pseudomonas aeruginosa isolates from burns patients. Indian Journal of Medical Research, 122: 324-329.

Shaw KJ, Rather PN, Hare RS y Miller GH. 1993. Molecular genetics of aminoglycoside resistance genes and familial relationships of the aminoglycosidemodifying enzymes. Microbiological Reviews, 57: 138-163.
Stain A y Raoult D. 2002. Colistin: An antimicrobial for the $21^{\text {st }}$ Century. Clinical Infectious Diseases, 35: 901-902.

Stratchounskil LS and the Russian NPRS Study Group, Kozlov RS, Rechedko GK, Stetsiouk OU y Chavrikova EP. 1998. Antimicrobial resistance patterns among aerobic Gram-negative bacilli isolated from patients in intensive care units: results of a multicenter study in Russia. Clinical Microbiology and Infection, 4: 497-507.

Tenover FC. 2006. Mechanisms of Antimicrobial Resistance in Bacteria. The American Journal of Medicine, 119(6A): S3-S10.

Vakulenko SB y Mobashery S. 2003. Versatility of aminoglycosides and prospects for their future. Clinical Microbiology Reviews, 16(3): 430-450.

Vallés J y Mariscal D. 2005. Neumonía por Pseudomonas aeruginosa. Enfermedades Infecciosas y Microbiología Clínica, 23(3): 30-36.

Vila J, Ruiz J, Navia M, Becerril B, García I, Perea S, López I, Álamo I, Ballester F, Planes A, Martínez J y Jiménez T. 1999. Spread of amikacin resistance in Acinetobacter baumannii strains isolated in Spain due to an epidemic strain. Journal of Clinical Microbiology, 37: 758-761.

Xu J, Moore J, Murphy P, Millar C y Elborn J. 2004. Early detection of Pseudomonas aeruginosa: comparison of conventional versus molecular (PCR) detection directly from adult patients with cystic fibrosis (CF). Annals of Clinical Microbiology and Antimicrobials, 3: 21.

Zurita J, 2005. Antibióticos aminoglucósidos. En: Fundamentos de Farmacología Médica: 1109-1119. Casa de la Cultura Ecuatoriana "Benjamin Carrión". Quito, Ecuador. 